\title{
HETERONORMATIVIDADE E PRODUÇÕES DE VIOLÊNCIAS LGBTFÓBICAS: ANÁLISE A PARTIR DA TEORIA QUEER
}

\author{
HETERONORMATIVITY AND PRODUCTION OF LGBTPHOBIA VIOLENCES: \\ ANALYSIS FROM THE QUEER THEORY
}

\author{
Uenderson Wesley Rodrigues Ribeiro e Rosângela da Luz Matos² \\ 1 Centro Universitário Jorge Amado, Brasil, e-mail: uendersonwesley@gmail.com, ORCID: \\ https://orcid.org/0000-0001-7259-2752 \\ 2 Universidade Federal de Ceará, Brasil, e-mail: profe.rosangela.matos@gmail.com, ORCID: \\ https://orcid.org/0000-0001-7764-9121
}

\section{A R T I C LE IN F O}

Article history:

Received 2020-05-01

Accepted 2020-11-30

Available online 2020-11-30
Palavras-chave: Heteronormatividade. LGBTfobia. Violência. Teoria Queer.

Keywords: Heteronormativity. LGBTphobia. Violence. Queer Theory.

RESUMO. O Brasil é campeão em violência contra LGBTs, no ano de 2018 foram registradas 420 mortes. $O$ presente artigo tem como objetivo analisar a literatura científica no que tange as produções de violências LGBTfóbicas tendo como pressuposto a heteronormatividade, sendo embasada pela Teoria Queer. Tem como método uma revisão de literatura sistemática. Foram analisados dez artigos empíricos encontradas nas bases de dado SciELO e Pepsic. Para escolha dos artigos foram utilizados alguns critérios de inclusão e exclusão. Em seguida, procedeu-se com a análise descritiva quanto a temática, objeto de estudo, metodologia, resultado e objetivo dos artigos incluídos nessa pesquisa. Os resultados indicam que existem formas de violências próprias na regulação das não-heterossexualidades e expressões de gênero dissidentes que produzem consequências danosas na saúde mental dessa população. Além de mostrar o caráter heteronormativizador das relações socias, desejos, identidades e políticas de reconhecimento.

ABSTRACT. Brazil is champion in violence against LGBTs, in the year 2018 there were 420 deaths. The present article aims to analyze the scientific literature regarding the productions of LGBTphobic violence with the assumption of heteronormativity, being based on by Queer Theory. Its method is a systematic literature review. Were analyzed ten empirical articles found in the SciELO and Pepsic databases. For choice of articles some inclusion and exclusion criteria were used. Then, we proceeded with the analysis descriptive as to the theme, object of study, methodology, result and objective of the articles included in this research. The results indicate that there are forms of violence specific to regulation of non-heterosexualities and dissident gender expressions that produce harmful consequences on the mental health of this population. Besides showing the character heteronormativizer of social relations, desires, identities and recognition policies. 


\section{Introdução}

Os dados dessa pesquisa foram discutidos no evento IV Seminário Internacional Desfazendo Gênero, ocorrida na cidade de Recife, no período de 13 a 15 de novembro de 2019. Este trabalho foi apresentado no Simpósio Temático (ST 23): Suicídio da População LGBTI: jogando luz às invisibilidades e peculiaridades, resultando assim, no convite da revista REVES para publicação.

A homofobia é um conjunto de violências que surgem com a homoafetividade sendo referenciada como estatuto de pecado e anormalidade psíquica, dentro das culturas judaicas-cristãs, possibilitando sanções normativas para o comportamento, este considerado imoral. (NASCIMENTO, 2010; FOUCAULT, 1988). Tais construções corroboram crenças que estão associadas à marginalização da população de Lésbicas, Gays, Bissexuais, Travestis e Transexuais (LGBT).

De acordo com Borrilo (2010) a homofobia é uma série de violências que se referem a um conjunto de práticas sociais a partir do ódio explicito e/ou implícito, persistentes ou não. Essa violência concretiza-se em agressões verbais, físicas, simbólicas e psicológicas, bem como negligência, indo até morte e tortura. A homofobia configura também a repressão de si e o descolamento dessa violência em outros setores da vida, produzindo a depressão e a atitudes autodestrutivas. (NASCIMENTO, 2010; BORRILO, 2010; TOLEDO E PINAFI, 2012).

Entretanto, para compreender homofobia como violência, é necessário entender violência. A violência é oriunda de um processo de não reconhecimento do outro como humano, provido de razão e liberdade, transformando-o em coisa. (CHAUÍ, 2017). É um processo que pode ocorrer intencionalmente lesão física ou psicológica, tendo como pressuposto uma relação e poder e é perpetrada contra um determinado grupo, pessoa ou a si mesmo, que resulte ou tenha como possibilidade de resultar uma série de danos morais, psicológicos, sociais e privação de direitos básicos. (KRUG et al., 2002). A violência também dever ser compreendida como histórica, produzida culturalmente, abrange diferentes classes e está presente nas relações intimas também, pois são todas marcados por relação de poder. (MINAYO, 2006).

O Grupo Gay da Bahia (GGB) disponibiliza dados anuais sobre o número de mortes de LGBT's no Brasil. No ano de 2018, o número chegou a 420, diminuindo em relação ao ano anterior que totalizou 445. Esses números são contabilizados a partir da veiculação de notícias sobre assassinatos e suicídios. Este número pode ser maior, tendo em vista que são subnotificações. De acordo com esses dados, a Bahia aparece em terceiro lugar no número de mortes de LGBT's, ficando atrás de São Paulo e Minas Gerais. Esses dados apontam que, o Nordeste do Brasil é a região que mais mata LGBT's. O Ministério de 
Direitos Humanos (MDH) realizou o levantamento dos dados sobre a violência contra LGBT's em 2018, reunindo dados de 2011 até 2016, disponibilizados pelo GGB, pelo Disque 100 e Rede Trans Brasil (RedeTrans). Sendo o Disque 100 o principal meio de recebimentos de denúncias relacionadas a população LGBT, este serviço, desde o período de 2011 até 2016 registrou 10.757 denúncias e 19.901 registros de violações.

De acordo com o trabalho de Teixeira-Filho (2012) jovens não-heterossexuais estão em maiores riscos à tentativa de suicídio, sendo três vezes mais propensos em relação a jovens heterossexuais e compreende $30 \%$ do suicídio juvenil. O trabalho de Hatzenbuehler (2011) mostra uma proporção de até cinco vezes mais se esses jovens estiverem inseridos em um contexto familiar repressivo. O suicídio é a segunda maior causa de morte de jovens de 15 a 29 anos, de acordo com os dados fornecidos pela OMS (2018). No Brasil é a quarta maior causa de morte de jovens da mesma faixa etária.

Com isso, a discussão sobre heteronormatividade e homofobia convoca a pensar estratégias para a compreensão das violências que permeiam a comunidade LGBT+. Embora as ciências das saúdes já tenham participado historicamente da patologização das dissidências sexuais e de gênero, corroborando para as representações sociais sobre esse fenômeno perdurarem até hoje, é dever destas mesmas ciências uma produção política e crítica, compreendendo as relações de poder que se estabeleceram, compreender o caráter sóciopolítico de suas produções. Fazem-se necessárias mais produções sobre o tema heteronormatividade tendo em vista a sua função de organização da vida social e as produções de violências na população dissidente de norma.

Assim o objetivo dessa pesquisa é analisar a literatura científica quanto à relação da heteronormatividade na produção da homofobia, tendo como referencial teórico a literatura Queer.

\section{Metodologia}

Para essa pesquisa foi utilizada uma revisão sistemática de literatura. A pesquisa de revisão sistemática se caracteriza pela possibilidade de potencializar os achados de uma pesquisa, pois consiste em, sistematicamente, organizar e refletir criticamente sobre a produção científica de um dado período de tempo. (KOLLER et al., 2014).

Para encontrar os artigos, foram utilizadas as bases de dados do Scientific Eletronic Library Online (SciELO) e Periódicos Eletrônicos em Psicologia (Pepsic). O SciELO é uma biblioteca de circulação de estudos científicos, mantido pela Fundação de Amparo à Pesquisa do Estado de São Paulo (FAPESP), em parceria com o Centro Latino-Americano e do Caribe de Informação em Ciências da Saúde (BAREME) e conta com o apoio do Conselho Nacional do Desenvolvimento Científico e Tecnológico (CNPq). Já o Pepsic é vinculado a Biblioteca Virtual de Saúde, mas voltado especificamente aos estudos em 
psicologia da América Latina.

As palavras-chaves que foram utilizadas são Homossexualidade com o operador booleano OR homossexuais AND "violência" OR homofobia OR agressão, no campo todos os índices. Nesta busca recolheu-se um total de 26 artigos. Considerando que para este artigo, foram analisados somente dez artigos procedeu-se o refino. O primeiro critério de inclusão que foram utilizados, eram: artigos publicados entre os anos de 2009 a 2018, português, completos e disponíveis para download, aplicados estes critérios, restaram 22 artigos. Estes 4 artigos foram excluídos por não estarem dentro das datas preconizadas para esse estudo.

Os critérios de inclusão subsequentes foram: a leitura dos títulos, resumos e artigos completos e em que seus resultados discutam sobre a homossexualidade masculina e violência, nesta ordem. Aplicado o segundo critério de inclusão restou-se os 11 artigos necessários à construção dessa pesquisa, pois em seus resultados não discutiam violência homofóbica. Um artigo foi excluído por discutir em seus resultados casamento em situação de restrição de liberdade, fugindo do proposto da pesquisa. Outro foi excluído por discutir contextos de vulnerabilidade do HIV/AIDS.

Para o número necessário de artigos, foi utilizado um critério de exclusão para retirar um artigo que em suas discussões traziam a violência por parceiro íntimo. Assim sendo, com o critério de exclusão posto, restaram os dez artigos para compor essa pesquisa.

\section{Desenvolvimento}

A LGBTfobia caracteriza-se pelo ódio ou aversão à população LGBT, explícitas ou implícitas, construídas em percursos históricos e sociais e, que no Brasil, toma forma própria de se constituir. Pode ser vista como processo de normalização das identidades dissidentes, seu controle e regulação, pautadas na heteronormatividade como pressuposto, tendo maneiras singulares de organização da violência, com tipologias próprias nestas regulações. (PEIXOTO, 2018; MISKOLCI, 2009). Também pode ser caracterizado como um medo irracional das homoafetividades e transgeneridades ou aqueles que a leitura presume sêlos. (NASCIMENTO, 2010). Esses discursos, fundamentados em diversos saberes sociais, como a religião, a ciência e a filosofia moral, tem como ponto de partida, a vigília. A vigília, técnica de controle pensada por Foucault (1987), tem como objetivo a observação sistemática de um sujeito, segundo práticas normalizadoras, em que panopticamente, o sujeito se autorregula tendo em vista, evitar as punições que decorrem deste processo.

A naturalização da violência se dá através de rituais simbólicos que, através da linguagem, fornece a essas subjetividades um status de anormalidade, dentro dos 
parâmetros de normalidade preconizada em nossa cultura judaico-cristã. Tais pressupostos tem como principal característica desde os períodos de colonização portuguesa no Brasil, a colonização do pensamento, bem como o controle dos corpos. Fica evidente que pessoas LGBT's foram e são ameaças à ordem e a ideologia dominante. (MISKOLCI, 2012; PEIXOTO, 2018; BADINTER, 1993). Contra a população LGBT, o discurso que hoje consideramos violência, foi-se naturalizado como prática regulatória, num processo histórico. Esse processo foi importante e necessário para construção de modos de controle e tentativa de mudança daqueles considerados imorais. Assim, essas violências além de não terem sido questionadas, eram também valorizadas, consentidas e incitadas. (PEIXOTO, 2018). A violência tem como pressuposto a tentativa de normalização da sexualidade e o gênero. Ligadas à modos de heterossexualização compulsória e heteronormatividade, a violência LGBTfóbica se caracteriza, principalmente por modos de representações sociais e saberes sobre as sexualidades e exercícios de gêneros dos sujeitos, que modula a forma em que homens e mulheres, juntamente com suas sexualidades devem se comportar e como seus corpos devem ser. (BUTLER, 2003).

Podemos traduzir queer como estranho, esquisito e excêntrico, não há tradução para a língua portuguesa, o que alguns autores possibilitam pensar termos semelhantes no Brasil, como viado, bicha, transviado. (MIRANDA, 2012). Esse termo foi criado para ser usado como pejorativo contra as pessoas de sexualidades e corpos desviantes. Entretanto, o uso da palavra sofreu uma ressignificação e foi-se construída uma teoria queer nos anos de 1980, reivindicando o queer como local de existência legítima. A teoria Queer tem como objetivo o estudo das identidades e da organização do desejo e da sexualidade nas relações sociais, buscando questionar o modelo binário de análise da existência, como homemmulher, homo-hétero, denunciando o caráter construído e os discursos em jogo para a produção de uma relação de poder. (MISKOLCI, 2009). Assim, a Teoria Queer possibilita uma análise pós-estruturalista das minorias sexuais, não em busca de uma verdade central, mas compreender e politizar estudos e provocar estranhamentos em suas construções para que possamos sair das lógicas, historicamente construídas, de sujeitos determinados, essencialmente biológicos e em estudos heterocentrados, buscando questionar papéis impostos na socialização heteronormativa. O estudo sobre heteronormatividade se desenvolve nos estudos queer e questiona a organização social partindo da heterossexualidade como relação de poder e hierarquização, como força normalizadora e pensando as violências LGBTfóbicas como consequência dessa organização social. (MISKOLCI, 2007).

Como uma grade inteligível que põe em coerência sexo-gênero-desejo, segundo Butler (2007), parece a heteronormatividade compulsória construir locais de existências, a partir de um discurso incessantemente reiterado sobre masculinidades e feminilidades que precisam ser seguidas, dentro de uma estrutura de performatividade, tendo como ideal algo 
imaginado. A partir da performatividade de Butler (2017), compreendemos então, que o gênero se constrói com os atos repetitivos, signos, gestos, tornando estável o gênero como algo dado e natural a partir de um dado biológico. Se essa regulação for transgredida, se destacam os anormais, possibilitando o estigma e a violência que a população LGBT sofre, além das sanções punitivas, normativas e disciplinares contra os corpos/subjetividades dissidentes. (FOUCAULT, 1988).

\section{Resultado e discussão}

Para aprofundar as questões que surgiram na análise descritiva dos artigos encontrados, surgiram principais violências que podem ser entendidas como tentativas de regulação e controle das identidades dissidentes. Os resultados e discussões, tendo como referencial teórico a teoria queer que tenciona e intensifica a produção de saberes diferentes das normas préestabelecidas em ciências heteronormativas, possibilitando analisar os discursos sobre violência emergidos durante a análise descritiva.

4.1 MORRA, SOFRA, ACEITE: as principais violências, seus danos e regulações na comunidade $L G B T$

As tipologias encontradas a partir da análise descritiva, refere-se as violências que estão dentro dos moldes que heteronormativizam corpos. Foram encontradas as seguintes violências: o isolamento e a ação coercitiva da família sobre a naturalização e internalização da sexualidade norma, pressões para a mudança da sexualidade, excluindo do sujeito a possibilidade de exercício de sua sexualidade. Há também o controle sobre o sujeito, a vigília sobre ele e as correções normalizadoras que são acompanhadas das agressões verbais. (SIQUEIRA et al., 2009; SOLIVA et al, 2014).

A violência física é caracterizada pelo uso da força para provocar lesões, traumas, feridas, dores ou incapacidades a outrem. De acordo com o trabalho de Soliva et. al (2014) com adolescentes LGBTs, a violência física comumente aparece em seus discursos. Em consonância com Mott e Cerqueira (2003) os jovens homoafetivos são os principais alvos de violências deste tipo. A cada quatro casos de violências resgistrados no Brasil contra LGBTs, três são com homens gays. (MDH, 2018).

A violência simbólica é caracterizada pelo estabelecimento de uma norma, uma regulação de práticas sociais em que as punições se estabelecem de forma sutil como o silenciamento e o apagamento do sujeito. Estas violências se apresentam, como: expulsão de casa, perseguição, repressão das vivências homoafetivas, silenciamento do sujeito, 
tentativa de realocação da sexualidade a partir do "afeto" familiar. Além disso, destaca-se a dificuldade ao acesso a serviços básicos de saúde, à proteção social, à escolarização e emprego. Outras formas aparecem no âmbito profissional, como: desqualificação para um cargo, silencia mento quando não tratam do assunto, invisibilização. (BRAGA et al., 2018).

A violência sexual diz respeito a práticas em que ocorrem nas relações como exercício de poder sobre outrem e visa utilizar a vítima como forma de obtenção de prazer sexual em práticas eróticas por meio da imposição e força, aliciamento e ameaça, tendo em vista a violação do corpo de outro sujeito. Esta forma de violência aparece nos discursos das pessoas LGBT como uma das que estão presentes em suas vidas e se expressam como: assédio sexual, ameaça e tentativa de abuso e o próprio estupro. (NATARELLI et al., 2015). Leva-se em consideração que os estudos de Teixeira-filho e Rondini (2012) apontam que pessoas não-heterossexuais tem aproximadamente duas vezes mais chances de sofrer esse tipo de violência.

Além disso, há a finalização e o extermínio desses corpos materializados nos relatórios disponíveis pelo GGB, na qual em 2017 foram registradas 445 mortes violentas contra pessoas LGBTs. Já em 2018, houve uma redução de 25 mortes e perfaz o total de 420, o que significa que a cada 20 horas um LGBT é assassinado ou comete suicídio. Os principais instrumentos para cometer os assassinatos, são: arma de fogo, seguidas por armas brancas, agressões físicas: espancamento, asfixia, pauladas, apedrejamento, fogo para queimar o sujeito. A maioria destas ocorrem nas vias públicas.

O processo de saída do armário, descrito como um dos marcos da vivência LGBT que é o ato de "revelar", "contar" sobre a sexualidade e o gênero dissidente é uma fase marcada por violências. Esse momento envolve diversos processos que geram sentimentos, como: medo da perda da afetividade familiar, perda do apoio financeiro, vergonha de si, gerando angústia e sofrimento. Esse processo também causa isolamento, o que pode acumular uma tensão na tentativa da mudança da sexualidade dissidente para a norma. (SOLIVA e JUNIOR, 2014; BRAGA et al., 2018). Há também afastamento de grupos de referências por medo da exposição a possíveis represálias e também a tentativa de se manter não assumido para que não haja as discriminações domésticas presente nas existências dissidentes. Além disso, pode causar também uma difusão da visão de mundo, representações e sentimentos negativos em relação a própria homossexualidade e identidade de gênero, tendo como sentimento a humilhação, vergonha de si e o constrangimento em falar sobre si próprio, reproduzindo discursos impostos pela família, na tentativa de uma naturalização de uma sexualidade norma. (SOLIVA e JUNIOR, 2014; BRAGA et al., 2018).

Verifica-se um mecanismo regulatório, conhecido como "homofobia internalizada". Estas construções assumem funções devastadoras na construção da subjetividade, se 
assujeitar e se assumir perante a norma vigente traz impactos na sua autoestima, podendo provocar desconforto e mal-estar na própria experimentação da homoafetividade e vergonha frente a possibilidade de ser identificado como tal. (MONDIMORE, 1998). Tais sentimentos refletem a vergonha de si, culpa e a tentativa de enquadre na norma. A homofobia internalizada configura então a repressão de si e o descolamento dessa violência em outros setores da vida, produzindo a depressão e as atitudes autodestrutivas e heterodestrutivas. Frequentemente observa-se também o ódio de si mesmo projetado no outro. (NASCIMENTO, 2010).

Sobre os processos normalizadores encontrados nos artigos, muitos deles refletem sobre a heteronormatividade como processo poderoso de regulação dos corpos na nossa sociedade, produzindo formas de agenciamento, como um modo de produzir efeito, que desembocam na heterossexualidade uma forma única e natural de existência legítima. Reverberando na cultura, modos e práticas de um fazer em relação ao outro diferente. (ALBUQUERQUE et al., 2016; SOLIVA e JUNIOR, 2014; BRAGA et al., 2018; TEIXEIRAFILHO et al., 2011).

A construção desses saberes sobre a homoafetividade, fora reivindicada nos discursos religiosos, em que considera as práticas homoerótica e identidades transgêneras como desviante e imoral, sendo visto como um pecado. (SOLIVA e JUNIOR, 2014; NASCIMENTO, 2010; TEIXEIRA-FILHO et al., 2011). Alinhado a isso, a visão religiosa judaico-cristã construída sobre estas identidades também considera a violação das leis divinas da procriação, ou seja, a continuação da família, como já denunciada por Foucault (1988).

O discurso científico do século XIX é essencialmente subordinada a práticas moralistas, cujas práticas se reiteram em discursos médicos (FOUCAULT, 1988). Dessa maneira, não tem como pensar enunciados científicos desvinculados dos discursos sociais que imperava no contexto em que ele se insere. A sexualidade é construída a partir da lógica reprodutiva, calcadas no cristianismo indo para os enunciados científicos para ganhar legitimidade e validação. Alinhada ao estigma e a discriminação social, esses enunciados científicos que colocam as existências dissidentes como passíveis de cura, começaram a circular no corpo social, criando representações sociais sobre estas existências como doença. Tendo em vista a violência que isso causou, as relações afetivo-sexuais aconteciam de forma privada, em ambientes clandestinos. (ALBUQUERQUE et al., 2016; SOLIVA e JUNIOR, 2014; BRAGA et al., 2018).

Pode-se observar então, que o que historicamente Foucault (1988) chamou de dispositivo da sexualidade, ganha releituras quando encontramos na cisheteronormatividade a regulação dos corpos, principalmente daqueles que desviam da norma. Este mecanismo, 
indica o aspecto machista e cisheteronormativizador da nossa sociedade, que hierarquiza existências e inferioriza o gênero feminino e pessoas não-heterossexuais.

\section{Considerações Finais}

A heteronormatividade, pressuposto regulador dos afetos, modos de funcionamento do desejo, corpo e relações, desemboca na LGBTfobia práticas punitivas que incidem na tentativa de normalizar um corpo que é dissidente. Essas práticas evidenciam a violência estrutural e simbólica, na qual, a heteronormatividade produz. Com isso, podemos dizer que a heteronormatividade e a homofobia influenciam a morte de pessoas LGBT's, produzindo além dessas violências explícitas e vindas do outro, violências contra si mesmo, marcadas por uma homofobia interiorizada, em que os discursos sobre si são marcados pelos discursos violentos que o formam.

No Brasil a retirada da homossexualidade como patologia mental é retirada em 1985, pelo Conselho Federal de Medicina. O Conselho Federal Psicologia lança no ano de 1999, a norma referente as questões ligadas a homoafetividade, a resolução de №001/99 que "Estabelece normas de atuação para os psicólogos em relação à questão da Orientação Sexual", retirando o caráter patologizante das sexualidades dissidentes. Embora os estudos sobre sexualidades ainda tenham como pressuposto uma norma, ainda faltam mais pesquisas que forneçam e denunciem a heteronormatividade como uma poderosa estrutura discursiva que forma corpos, violenta outros e regula práticas sociais baseadas em uma ideia de normal, que não incluem não-heterossexuais. A teoria queer possibilita essa análise tendo como orientação uma construção baseada no questionamento dessas estruturas rígidas de poder.

Assim, esta pesquisa possibilitou mostrar como a heteronormatividade é um dispositivo histórico e cultural e que produz violências àqueles que não estão dentro da norma, evidenciando estas violências como forma de punição e regulação social, criando uma hierarquia sobre as existências que organiza modos de funcionamento e relações, além de mostrar como estão estruturadas as violências e as consequências destas na vida dos sujeitos, pode-se dizer que estas violências são resultantes das concepções heteronormativistas da existência. Com isso, é necessário difundir, produzir, incitar e construir referências e práticas de cuidado que não utilizem uma norma heterossexista para se produzir. Isso possibilita um fazer plural, que leva em conta modos de existências e subjetividades, produzindo além de tecnologia de cuidados e aceitação da diferença, produção política que transformem saberes e dinamizem as relações sociais na garantia dos direitos. 


\section{Referências}

ALBUQUERQUE, Grayce Alencar et al. Violência psicológica em lésbicas, gays, bissexuais, travestis e transexuais no interior do Ceará, Brasil. Saúde debate, Rio de Janeiro, v. 40, n. 109, p. 100-111, jun. 2016. Disponível em $<$ http://www.scielo.br/scielo.php?script=sci_arttext\&pid=S0103-

11042016000200100\&lng=pt\&nrm=iso>. Acesso em 13 set. 2018.
http://dx.doi.org/10.1590/0103-1104201610908.

BORRILLO, Daniel Homofobia: história e critica de um preconceito / Daniel Borrillo; [tradução de Guilherme João de Freitas Teixeira]. - Belo Horizonte: Autêntica Editora, 2010. BRAGA, lara Falleiros et al. Violência familiar contra adolescentes e jovens gays e lésbicas: um estudo qualitativo. Rev. Bras. Enferm., Brasília, v. 71, supl. 3, p. 1220-1227, 2018. Disponível em <http://www.scielo.br/scielo.php?script=sci_arttext\&pid=S003471672018000901220\&lng=pt\&nrm=iso >. Acesso em $14 \quad$ set. 2018. http://dx.doi.org/10.1590/0034-7167-2017-0307.

BUTLER, Judith. Problemas de gênero: feminismo e subversão da identidade. Judith Butler; tradução, Renato Aguiar. - Rio de Janeiro: Civilização Brasileira, 2003.

CHAUÍ, Marilena de Souza; ITOKAZU, Ericka Marie; CHAUI-BERLINCK, Luciana. Sobre a violência. [S.I: s.n.], 2017.

FOUCAULT, Michel. História da sexualidade I: A vontade de saber, tradução de Maria Thereza da Costa Albuquerque e J. A. Guilhon Albuquerque. Rio de Janeiro, Edições Graal, 1988.

FOUCAULT, Michel. Vigiar e punir: nascimento da prisão; tradução de Raquel Ramalhete. Petrópolis, Vozes, 1987. 288p.

HATZENBUEHLER, M. L. (2011). The social environment and suicide attempts in lesbian, gay, and bisexual youth. Pediatrics, 127(5), 896-903. doi:10.1542/peds.20103020.

KRUG EG et al., eds. World report on violence and health. Geneva, World Health Organization, 2002.

MINAYO, Maria Cecília de Souza. Violência e Saúde. Maria Rio de Janeiro : Editora FIOCRUZ, 2006. 132 p. (Coleção Temas em Saúde).

MISKOLCI, Richard. Queer Theory and Sociology: the challenging analysis of normalization. Sociologias 21, p. 150- 182, 2009.

NASCIMENTO, Márcio Alessandro Neman do. Homofobia e homofobia interiorizada: produções subjetivas de controle heteronormativo? Athenea Digital. Revista de pensamiento 
e investigación social, [S.I.], p. 227-239, mar. 2010. ISSN 1578-8946. Disponible en: <http://atheneadigital.net/article/view/n17-nascimento>. Fecha de acceso: 05 oct. 2018 doi: http://doi.org/10.5565/rev/athenead/v0n17.652

NATARELLI, Taison Regis Penariol et al. 0 impacto da homofobia na saúde do adolescente. Esc. Anna Nery, Rio de Janeiro, v. 19, n. 4, p. 664-670, dez. 2015. Disponível em $<$ http://www.scielo.br/scielo.php?script=sci_arttext\&pid=S141481452015000400664\&Ing=pt\&nrm=iso>. Acesso em 14 set. 2018 . http://dx.doi.org/10.5935/1414-8145.20150089.

ROSELLI-CRUZ, Amadeu. Homossexualidade, homofobia e a agressividade do palavrão: seu uso na educação sexual escolar. Educ. rev., Curitiba, n. 39, p. 73-85, abr. 2011. disponível em <http://www.scielo.br/scielo.php?script=sci_arttext\&pid=S010440602011000100006\&lng=pt\&nrm=iso>. Acesso em 23 set. 2018. http://dx.doi.org/10.1590/S0104-40602011000100006.

SIQUEIRA, Marcus Vinicius Soares et al. Homofobia e violência moral no trabalho no Distrito Federal. Organ. Soc. [online]. 2009, vol.16, n.50, pp.447-461. ISSN 1984-9230. http://dx.doi.org/10.190/S1984-92302009000300003.

SOLIVA, Thiago Barcelos; SILVA JUNIOR, João Batista da. Entre revelar e esconder: pais e filhos em face da descoberta da homossexualidade. Sex., Salud Soc. (Rio J.), Rio de Janeiro, n. 17, p. 124-148, ago. 2014. disponível em $<\mathrm{http}: / / w w w . s c i e l o . b r / s c i e l o . p h p ? s c r i p t=s c i \_a r t t e x t \& p i d=S 1984-$

64872014000200124\&lng=pt\&nrm=iso>. Acesso em 14 set. 2018 . http://dx.doi.org/10.1590/1984-6487.sess.2014.17.08.a.

TAQUETTE, Stella Regina; RODRIGUES, Adriana de Oliveira. Experiências homossexuais de adolescentes: considerações para o atendimento em saúde. Interface (Botucatu), Botucatu, v. 19, n. 55, p. 1181-1191, dez. 2015. disponível em $<\mathrm{http}: / / w w w . s c i e l o . b r / s c i e l o . p h p ? s c r i p t=s c i \_a r t t e x t \& p i d=S 1414-$

32832015000401181\&lng=pt\&nrm=iso>. Acesso em 23 set. 2018. Epub 21-Ago2015. http://dx.doi.org/10.1590/1807-57622014.0504.

TEIXEIRA-FILHO, Fernando Silva; RONDINI, Carina Alexandra. Ideações e tentativas de suicídio em adolescentes com práticas sexuais hétero e homoeróticas. Saúde soc., São Paulo, v.21, n.3, p.651-667, set. 2012. Disponível em . Acesso em 14 set. 2018. http://dx.doi.org/10.1590/S0104-12902012000300011.

TEIXEIRA-FILHO, Fernando Silva; RONDINI, Carina Alexandra; BESSA, Juliana Cristina. Reflexões sobre homofobia e educação em escolas do interior paulista. Educ. Pesqui., São Paulo, v. 37, n. 4, p. 725-741, dez. 2011. Disponível em $<\mathrm{http}: / / w w w . s c i e l o . b r / s c i e l o . p h p ?$ script=sci_arttext\&pid=S1517- 
97022011000400004\&lng=pt\&nrm=iso>. Acesso em 23 set. 2018 . http://dx.doi.org/10.1590/S1517-97022011000400004.

TOLEDO, Lívia Gonsalves; PINAFI, Tânia; A clínica psicológica e o público LGBT. Psicol. Clin. Rio de Janeiro, v. 24, n. 1, p. 197-163, 2012. Disponível em: http://www.scielo.br/scielo.php?scipt=sci_arttext\&pid=S0103-

56652012000100010\&1ng=en\&nrm=iso. Acesso em 04 out. 2018. http://dx.doi.org /10.1590/S0103-56652012000100010. 